\title{
ALEXEY BORISOV MEMORIAL VOLUME
}

DOI: $10.1134 /$ S1560354722010014

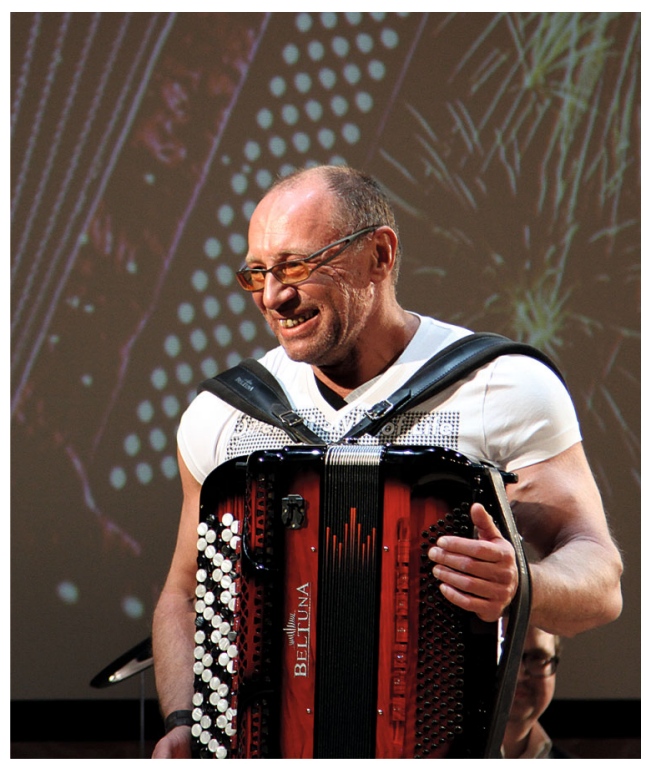

A year has passed since Alexey Borisov, a brilliant scientist and the founder and editor-in-chief of the journal Regular and Chaotic Dynamics, passed away. The editorial board is starting a memorial volume of RCD and intends to publish throughout this year papers which his friends, colleagues, students and followers from all over the world have prepared in memory of him. In our opinion, this is the best way to pay tribute to Alexey and his distinguished achievements ${ }^{1)}$.

Several publications ${ }^{2)}$ about Alexey Borisov's life and his legacy appeared last year. At the end of the year 2021, a memorial conference Regular and Chaotic Dynamics ${ }^{3)}$ took place. The talks given at the conference were accompanied by warm and grateful recollections of Alexey. The next (eighth) of the series of conferences Geometry, Dynamics, Integrable Systems ${ }^{4)}$, which were cofounded and coorganized by him, will also be dedicated to his memory.

We hope that all what Alexey Borisov created during his short, but bright life will continue to develop and flourish, thereby preserving the memory of this extraordinary, talented and charismatic man.

Editorial Board January 17, 2022

\footnotetext{
${ }^{1)}$ For a complete list of publications by A. V. Borisov, please visit: http://ics.org.ru/publications/index . php?author=23

${ }^{2)}$ In English, e.g.: In Memory of Professor Alexey V. Borisov (27.03.1965-24.01.2021), Regul. Chaotic Dyn., 2021, vol. 26, no. 2, pp. 113-118; Dragović V., Jovanović B., Gajić B. In memoriam: Alexey Vladimirovich Borisov (1965-2021), Theor. Appl. Mech., 2021, vol. 48, no. 2, pp. i-iii.

3) The international conference "Regular and Chaotic Dynamics", November 22-December 3, 2021, Moscow, Russia, http: //regular-and-chaotic-dynamics.info

${ }^{4)}$ The 8th International conference "Geometry, Dynamics, Integrable Systems — GDIS 2022", June 5-10, 2022, Zlatibor, Serbia, http://www.mi.sanu.ac.rs/ gdis2022/index.html
} 